\title{
Public Sector Performance Management in Africa: Reforms, Policies and Strategies
}

\author{
O. E. Okeke-Uzodike \\ P. Chitakunye \\ School of Management, IT and Governance, University of KwaZulu-Natal, \\ Pietermaritzburg Campus, KwaZulu-Natal, South Africa
}

\section{Doi:10.5901/mjss.2014.v5n26p85}

\section{Abstract}

Although public sectors in African countries differ due (largely) to diverse cultural settings, they nevertheless share a common challenge of weak performance in the area of service delivery. Often, such poor performance can be traced to political, social, economic, and environmental factors. Effective management of service delivery not only requires public sectors to have welltrained or skilled human resources in place, but also that they imbibe appropriate workplace values such as a competitive edge and strong customer focus, underpinned by a commitment to accountability and responsiveness to the needs of the citizenry. In the quest to provide and maintain the needs of citizens, countries have increasingly embarked on various public service reforms. This paper centers on the relationship between performance management and recruitment policies in the public sector within Africa citing examples from South Africa and Nigeria. It examines the link between recruitment policies and the outcome of implemented and the ongoing government reforms in Africa towards achieving the Millennium Development Goals. The research design is based on secondary data. The findings suggest institutional capacity as a pre-requisite towards achieving MDG's and various national goals. The recommendations are made incorporating lessons learnt and way forward towards post MDG's target year.

Keywords: Public sector, performance management, reforms, policies, strategies.

\section{Introduction}

In most African countries, public service is a product of the colonial masters transferred to the indigenes at independence and of late, most African states have modified public service to suit their cultural diversity. However, African public sectors seem to be constantly facing challenges of service delivery in the quest to be accountable, customer focused and responsive to the needs of the citizens. According to Perotti (2003), "governments' involvement in the provision of goods and services has generally been characterized by inefficiency, poor performance and a lack of delivery of basic services". As such public sectors have been stigmatized with poor service delivery leading to weak performance management.

Given this context, the need for result oriented public service saw the birth of various public service reforms. Reforms are mostly about changing the way government work so as to return amongst others professionalism, meet up with citizens' demand, and achieve the goals and objectives of the government.The main factors leading to public sector reforms can be traced back to the following criteria, namely "the redefinition of the role of the state, secondly, the introduction of new measures to enhance public management performance and lastly, the emphasis of governments to adhere to the principles of good corporate governance through increased transparency, openness, accountability and increased citizen participation"(Keyter, 2007). There have been three waves of public service reforms in Africa namely; structural reforms-experienced in the early 1980's; capacity building-experienced in the 1990's and the ongoing service delivery improvement which came into existence in the early 2000's (Mutahaba\&Kiragu 2002). The reason behind 2000's reform was the need to demonstrate early results, public demands for transparency and accountability, influence of new public management, the need to support sector wide approaches, and an integrated systems approach. From the academics and policy practitioners perspective, "much emphasis was laid on measures for enforcing the accountability of the governors to the governed through increased transparency, openness, and citizen participation" (Mutahaba\&Kiragu, 2002).

In the year 2000 which marked the beginning of the new millennium, The United Nations in collaboration with the New Partnership for Africa Development (NEPAD) launched the eight developmental goals targeted for the year 2015. These goals were considered prerequisite for social development, the ability to harness technological opportunity and enable environmental sustainability. These goals are: 
- Eradication of extreme poverty and hunger

- Achievement of universal primary education

- Promotion of gender equality and empowerment of women

- Reduction in child mortality

- Improvement of maternal health

- Combating HIVIAIDS, malaria and other diseases

- Ensuring environmental sustainability

- Developing a global partnership for development (UNDP, 2010)

The priorities outlined in the New Partnership for Africa's Development (NEPAD) were aligned to that of MDG's and include;

- Poverty reduction

- Investment in human resources

- Mobilization of resources

- Good governance

- Economic growth

- Global partnerships

- Environmental protection (ECA 2003)

These goals were assumed to be key drivers towards to effective public service.

However, this paper examines the contribution of human resource management principles and techniques-recruitment policies as a toolkit in achieving the MDG goals. Much attention on service improvement reforms have been devoted to individual performance systems such as the use of incentives. There has been less emphasis on improving performance by ensuring that the recruitment policies guiding the processes and procedures for recruitment are duly followed. As a result, it is deemed necessary to explore the link between performance management and recruitment policies. Specifically, the paper focuses on the public service reforms initiated and implemented from the start of the new millennium. It will ascertain the extent the public services reform has reached by measuring various performances and outcome in African states towards achieving developmental goals. In discussing the outcome of various reforms adopted in the African public service, this paper begins by raising conceptual issues in the introductory section. It goes on in the second section to identify the theoretical concept underpinned by the title. The third section discusses the relationship between performance management and recruitment policies. The fourth section reviews the various public sector reforms adopted in African countries. The fifth section discusses the imperatives/drawback on the public sector performance and finally the sixth section is the concluding section which looks into the future based on the findings and suggests measures aimed at improving performance of public services towards ensuring that goals and objectives are achieved.

\section{Theoretical Concept}

Citizens perceive good governance is the bedrock of reform programs evident from the quality of services provided by the government.This is why Omoyefa(2008), pointed out that "efficiency, effectiveness, and responsiveness of government to the yearning of its citizens could only begauged through the lenses of the public sector reform". In regards to this statement, this paper adopts a combination of the new public management and human resource management models --Harvard model.

The new public management model is a concept which came into existence in the late seventies and early eighties as "a label used to describe a management culture that emphasizes the centrality of the citizen or customer, as well as accountability for results" (Amako2004). The idea was borrowed from private sector to enhance the efficiency and effectiveness of public sector through human resources. The human resource management model emphasizes on human resource management policy choices and human resource outcomes. The policies adopted by the government can lead to positive short or long term outcomes or vice versa. The positive outcome might result in individual/organizational effectiveness, leading to achieving the stated goals (Katou\&Budhwar2006). To support this outcome, the new public management concept highlights the importance of performance management amongst others as a management tool required to place the organization at a competitive edge. Ultimately, the significance of these theories lies in the importance of decision making in recruitment processes. The decisions and strategies regarding recruitment of human resource reflect in the organizational performance.However, "effective and fair selection practices for the strategic deployment of highly motivated and competent employees are important vehicles for enterprises to gain a competitive advantage" (Brewster, Carey, Dowling, Grobler, Holland \&Warnich, 2003). It therefore means that the concept of new public management and human resource management policies would set the organization to perform better in this era of 
globalization. The resultant effect is an increase in transparency, accountability and responsiveness of government towards delivery of services to the citizens.

\section{Relationship between Performance Management and Recruitment Policies}

According to Richard, Devinney, Yip \& Johnson (2009), "organizational effectiveness captures organizational performance plus the myriad internal performance outcomes normally associated with more efficient or effective operations and other external measures that relate to considerations that are broader than those simply associated with economic valuation (either by shareholders, managers, or customers), such as corporate social responsibility". However, identifying the link between recruitment policies and organizational performance is a critical issue for public sector policy makers and employees. According to Du Toit, Knipe, van Niekerk, van der Waldt, and Doyle (2002), "performance management is about managing systems which translate strategicgoals into individual performance terms through human resource management". On the other hand, recruitment policies define "the objective of the recruitment and also provides a framework for the implementation of the recruitment program" (Richards, 2011). The implementation of the recruitment program requires a set of rules to guide employment processes and procedures thus referred to as recruitment policy. The way in which these policies are applied reflects in the overall performance of the organization. This is why Kreitner\&Kinicki, (2010) noted that "the success or failure of public sector business organizations hinges on the ability to attract, develop, retain, empower and reward a diverse array of appropriately skilled people and is the key to improving organizational performance.

It is a general belief that motivation of employees will produce result oriented employees. That is, employees' skills, knowledge, merit, motivation and job performance are purported to be mediating path between human resource management and organizational performance outcomes. The question is what if less qualified candidates are employed as a result sentiments? Literature has documented cases of recruitment processes being influenced by political sentiments. Citing examples from African states, in Nigerian public service, perceptions of nepotism, ethnicity, political patronage and socio-economic connections are much in existence and forms part of the basis for determining who get employed in the civil service(Fajana, Owoyemi, Elegbede\&Gbajumo-Sheriff 2011). Similarly, in South Africa, scholars have cited various reasons for the civil society protests which include amongst others; maladministration, perception of incompetence, nepotism within local government structures, and the deployment of ANC 'comrades' to positions for which they are not qualified (Kanyane, 2010; Burger, 2009; Fourie\& de Jager, 2005).

Going by the report of the Third Biennial Pan African Conference (2001),one of the principles of the framework adopted by most African governments to guide public service is that: "the relationship between the Public Service and its public servants is to be based on professional merit (that is you will become a public servant if you deserve it as a professional) and respect for human rights (equal opportunities for all, especially women, persons with disabilities, and particularly disadvantaged groups)". However, adherence to meritocracy has been a challenging task facing African governments. Within this framework, Mihalic(2004) defined adherence as "whether a policy, practice, service or intervention is being delivered as it was designed or written". In as much as African public service is modified within the cultural background of the society and the policies capture conditions of recruitment such as affirmative action; it is without doubt that incorporating meritocracy in the recruitment process will stimulate public sector efficiency and effectiveness.

\section{Review of Various Public Sector Reforms in Africa}

Over the past three decades, African countries have been reforming their public sectors with a view to improving efficiency, effectiveness, accountability and transparency as part of efforts to improve the delivery of public servicesOSSREA (2013). In addition, Hughes (2003) stated that reforms to performance management are particularly important part of the managerial programme aimed at improving the progress of the both individual and organization towards achieving objectives. Public sector reforms are imbibed in the principles of new public management and actions have included privatization, public/private partnerships, commercialization and adoption of private sector approaches in managing public organizations. In the process of replicating the practices of private organizations into the public service, there is a total overhauling of the government administrative machinery with the aim of injecting real effectiveness, efficiency, hard core competence, and financial prudence in the running of the public sector; deliberately changing theinterlocking structures and processes within the publicsector that define how financial and physical resourcesand people are deployed and accounted for (Omoyefa, 2008; World Bank 2012).

In recognition of the challenges facing African countries in the areas of public service delivery, various reforms 
have been introduced focusing on service delivery in different sections of government management systems aimed at improving efficiency and effectiveness of public services towards achieving various national goals and MDG's. Such reforms have been evident in the financial management systems, administration and human resource management. Specifically,

- The financial management systemsaw the birth of Public Financial Management (PFM) aimed at enhancing fiscal discipline, redirecting public expenditure to poverty reduction; enhancing efficiency and effectiveness of public expenditures; and improving transparency and accountability in the use of public resources (ADB 2012).

- Administrative reforms emphasizes on building capable states that are able to foster dynamic partnership with civil society and the private sector, improve the quality of the service delivery, enhance social responsibilities and ensure the broader participation of all stakeholders and feedback on public performance to the policy makers (UNDP, 2007).

- Human resource management system: Improvement of skills within the public sector (capacity development).

However, the implementation of these reforms reflected varying results on country basis. For example, the South African government introduced a framework -The Medium Term Strategic Framework (MTSF, 2009-2014) in line MDG's that identifies the developmental challenges with the following objectives:

- Halve poverty and unemployment by 2014.

- Ensure equitable distribution of the benefits of economic growth and reduce inequality

- Improve the nation's health profile and skills base and ensure universal access to basic services

- Build a nation free of all forms of racism, sexism, tribalism and xenophobia

- Improve the safety of citizens by reducing incidence of crime and corruption(UNDP:2010)

Indeed the integration of various reform initiatives reflected mixed results. As such government review report claimed that over two and half million houses have been built for the poor giving shelter to over ten million people; 8.1 million consumer units were receiving electricity from municipalities and service providers; 2.8 million (34.8\%) consumer units had access to free basic electricity; the total number of consumer units that received free basic water services increased by 16.3\% (from 9.9 million to 11.5 million) between the 2007 and 2008 financial years.(United Nations, 2013a; NPC, 2011). Moreover, post-apartheid government has prioritized various policy frameworks (such as Reconstruction and Development Programme (RDP), the National Growth and Development Strategy (NGDS) and the Growth, Employment and Redistribution Strategy (GEAR) and anti- poverty strategy (Poverty Alleviation Fund); claiming the population living below the poverty line of a $\$ 1$ per day has been halved thus achieving MDG 1. Irrespective of these improvements, yet poverty does remains one of the most developmental challenges facing South Africa (UNDP, 2010). Media showcase angry citizens demonstrating about poor service delivery almost on daily basis. A researcher has opined to, "government attempts to improve service delivery have not been sufficient to assuage the frustration and anger of poor people in South Africa" (Alexander, 2012). Literature has also documented that with South Africa's supportive policy and funding environment, a review of the country's progress towards the MDGs showed insufficient progress in the health sector (MDG's 4,5and 6 respectively--- reduction in child mortality, improvement of maternal health and combating HIVIAIDS, malaria and other diseases- Chopra et. al 2009a). This is why South Africa is viewed as a country with a paradox of apparent progress yet worsening health outcomes (Chopra et.al 2009b).

Similarly, in Nigeria, the government introduced medium and long term reform initiatives aligned to target each MDG. The national development strategies saw the birth of National Economic Empowerment and Development Strategy (NEEDS- with actionable goals of wealth creation, employment generation, poverty reduction and value re-orientation), which was extended to states and local governments as SEEDS and LEEDS respectively. In addition, the federal government envisaged placing Nigeria among the top 20 leading economies in the world; Nigeria vision 20: 2020 and 7Point Agenda comprising sustainable growth in the real sector of the economy, improvement of infrastructural (power, energy and transport), agriculture and agro-industry development, human capital development (education and health), security, law and order (including electoral reform), combating corruption and conflict resolution through promoting equitable and sustainable regional development (Niger Delta development) (OSSAP-MDG's: 2010). The Nigerian government also introduced widely acknowledged innovative initiatives to reduce poverty and improve public service performance. Such was evident in the pioneering schemes such as the Virtual Poverty Fund that tags and tracks funds allocated to poverty reduction from debt relief; compulsory free basic education; conditional cash transfer to the vulnerable for social protection; conditional grant scheme; federal grants to support MDGs investment by states and local governments; all of these were in the determination to achieve the MDGs and re-position Nigeria (NPC: 2010). As the target year 2015 draws closer, the need to speed up with government commitment led to the introduction of a new 5-Year (2010-2015) Countdown Strategy closely linked with Nigeria's medium and long term - Roadmap to Accelerate Nigeria's Progress Towards achieving the Millennium Development Goals with the following objectives: 
- Improving the governance and accountability environment

- Strengthening coordination and cooperation among the three tiers and arms of government

- Mobilizing and committing all communities and key stakeholders to the MDGs

- Ensuring effective mainstreaming of MDGs into overall national and sub-national development visions and plans(NPC: 2010).

However, the integration of the strategies and initiatives have reflected mixed results. Government claimed sustained growth in the economy with average GDP growth rate; gains in agriculture reduced the proportion of underweight children from $35.7 \%$ in the 1990 to $23.1 \%$ in 2008; nearly 9 out of 10 children (88.8\%) are now enrolled in school; reduced infant mortality from 100 per 1,000 to 75 per 1,000 between 2003 and 2008 (NPC, 2010). However, the United Nations Report on MDG's, indicated that Nigeria alongside with India account for more than a third of all deaths in children under five worldwide (United Nations, 2013). In addition, The Vision 2010 Committee Report reveals that: 50\% of Nigerians live below the poverty line; only about $40 \%$ have access to safe drinking water; about $85 \%$ of the urban population lives in single houses with more than 7 occupants on the average; only about $62 \%$ of Nigerians have access to primary health care; most Nigerians take less than one-third of the minimum required protein and vitamins(NPC, 2010; Edoh 2003).

Given this context, as the MDG's target year of 2015 draws closer, Africa is still battling with significant results on the MDG's generally. Citing examples from a few MDG's initiatives, 1.2 billion people are still living in extreme poverty; almost half the population live on less than $\$ 1.25$ a day; Sub-Saharan Africa has been considered home to world's highest out-of-school children; with a few exceptions from countries such as Gambia, Ghana, Malawi and Senegal; the rate of change in gender disparity has been slow with GPI rising by just a few points, from 0.76 to 0.83 between 1990 and 2011 (United Nations 2013). Furthermore, 500 million people today, in Sub-Saharan Africa do not have access to electricity and the most vulnerable people have not benefited from progress of reform initiatives;world's highest maternal mortality ratio, contraceptive prevalence of only 25 per cent, and low levels of skilled attendance at birth; nearly 1 in every 20 adults are infected, accounting for 69 per cent of the people living with HIV worldwide. (United Nations: 2013; Akosile, 2012; NPC, 2011). However, on the overall, the Millennium Development Progress report has shown that progress has been insufficient to reach the target year 2015 for almost all the MDG goals if the prevailing trends persist (United Nations, 2013).

\section{Imperatives/Drawback on Developmental Goals in Africa}

The various public services reforms in Africa have varying degrees of success or failure. Some countries have achieved administrative reforms by flushing ghost workers, pay increase, improved service quality, economic reforms, etcetera but sustainable improvement still remains meager in the lives of the citizens. In support of this, a UNDP report on the progress of MDG's in Africa noted amongst others that; Africa is the world's second fastest growing region, its rate of poverty reduction is insufficient to reach the target of halving extreme poverty by 2015; poverty reduction lags behind growth; inequality is undermining efforts to reduce poverty; quality of education remains a challenge; Africa still has the greatest burden of child and maternal deaths and food insecurity is a recurring challenge (UNDP: 2013)

Drawback on developmental challenges varies with in the environmental context of the country. For example, in Nigeria, according to MDG report, the poor implementation of MDGs has been characterized by weak supportive policy environment evident from eradication of extreme poverty, maternal mortality and environmental sustainability. Furthermore, deeply entrenched corruption, gross inefficiency, wastefulness, time and financial commitment, incapacity of human capital to carry out programs and coordination between the tiers of government have been considered contributory factors to developmental challenges (The Guardian, 27 November 2009 page 1;NMDG 2010). In terms of time and financial commitment, Nigeria started integration of the programinitiatives five years after the conception of MDG's and has not been committing the required one billion dollars annually to the program (Ndume, 2013). Similarly in South Africa, the challenges facing the achievement of the developmental goals have been traced among others to the incompetency of the human resource. There have been accusations of incompetent professionals appointed to senior management positions and undue political influence (Powell, 2012).

Generally, literature has labeled the reform initiatives in Africa 'poor' tracing it to the weak links within the chain and capabilities in terms of knowledge, skills, information, experience and other soft skills resulting in severe capacity and capability gaps (World Bank, 2012; OSSREA:2013). In addition, the availability, frequency and quality of poverty monitoring data remain low in Sub-Saharan Africa. Institutional, political and financial obstacles continue to hamper data collection, analysis and public access (United Nations, 2013).Such have been evident in management arrangements that weaken accountability; financial management schemes that allow funds to be channeled to personal accounts;formal 
laws and procedures which are not followed in practice-for example, many countries have meritocratic employment regimes de jure - but de facto, these often remain only partially enforced and provide insufficient protection against patronage or the sale of public posts" (World Bank, 2012).

\section{Towards Post MDG's Target Year: Lessons Learnt - Is there Hope for Africa?}

The targeted 15 years to create a difference in the lives of Africans is elapsing with little or no impact on the citizens. Post MDG requires re-examination of government policies and strategies. Lessons learnt will serve as bases for review of policies, strategies and implementation plans. The first step would be re-visiting the human resource capacity used in implementing government policies. Often times, media has reported incidences of poor performance of public sector arising from incompetent manpower. For example, in Nigeria, one of the challenges that slowed the progress of MDG initiatives were amongst others, lack of skills and capacity to implement initiatives (UNDP: 2013). The human capital capacity concept varies from professionalism to acquiring the skills and knowledge to training and development of the personnel. In public services, the concept of professionalism addresses the need for the employees to acquire skills, knowledge and embrace merit principles in recruitment and selection irrespective of affirmative action in place. An excerpt from The African Human Resources Managers' Network (APS-HRMnet) says:

'The quality of human resources is critical to the development of any country. Global, regional and national commitments to sustainable and poverty reduction such as the Millennium Development Goals (MDGs) need human capacities in the public, private, and civil society sectors to transform these commitments into results------' (UNPAN, 2009).

In essence, having capable manpower will result in the effective, efficient and accountable which will in turn attract foreign investments. Researchers have mostly aligned ensuring professionalism in the public service with training, development systems, coaching, mentoring but ensuring merit based recruitment processes (in addition to affirmative action) would be a strong foundation on which training will flourish.

However, post MDG target year would need to revisit the core elements of the third wave reform-resuscitation of the basic ethos of professionalism, loyalty, dedication, accountability, and transparency (United Nations 2003). Achieving these elements requires governments re-focus on building meritocracy, improving the quality of personnel management, practicing more transparent and competitive recruitment and selection procedures amongst others as early reform efforts (World Bank, 2003).

\section{Conclusion}

This article discussed public sector performance in relation to recruitment policies drawing evidence from various government reforms towards accomplishing government goals and objectives. Specifically, the performance was measured from the outcome of various reforms adopted in Africa towards achieving millennium development goals. The data from Nigeria and South Africa reflect similar experiences in other Sub-Saharan African countries. Indeed, the performance of every public sector requires support from internal (policies and strategies such as recruitment policies) and external (socio-economic and political) environments. According to Olaopa (2011), "the capacity of most public services in the world today to effectively and efficiently carry out their administrative functions is judged in global terms by the system of high performance management and progress". The high performance management and progress can only be achieved with competent human resource.

However, tremendous efforts and resources allocated to reforms has resulted in Africa being the world's second fastest growing region (source) yet challenges such as poverty still enclave the society resulting in many African countries haven't been able to come close to their goal of developing and transforming their societies. One expects that such growth would provide an enabling environment for job creation and poverty reduction rather high unemployment rate, high mortality rate etcetera are the resultant effect. Furthermore, effective health services, education and housing still remain out of reach for many communities. Growing number of literature have documented cultural diversity as a key contributor to the various challenges facing performance management in the public sector. Irrespective of the diversity, less attention has been given to the capacity of human resource in the public sector. Evidence from the data has revealed that the success of various reforms in Africa has been mostly hindered by lack of professionalism. In the pursuit of fair representation, political patronage and nepotism, less qualified people have been found employed in strategic positions where they are struggling to perform.

Drawing on evidence from the research conducted by the World Bank (2003), which identified rule of law, meritocracy and good governance as key principles for public service reforms and performance improvement strategies, 
it is obvious that the relationship between recruitment policies and performance management cannot be out looked. With a few exceptions of successful cases (Botswana, for example), public service management remains at a lethargic stage (Economic Commission for Africa, 2003). Sustainable reforms and a result orientated public sector can only be achieved with competent human resource. Appropriate recruitment policies and practices are vital for African governments to achieve their respective goals and objectives.

\section{References}

African Development Bank Group. (ADB) (2012). Public Financial Governance Reforms: The Recent Progress in Africa.Governance, Economic and Financial Management Department

Retrieved fromwww.afdb.org

Akosile A. (2012), Achieve MDGs before 2015 Deadline, Nigeria, Others, Urged.Retrieved from http://www.thisdaylive.com/articles/achieve-mdgs-before-2015-deadline-nigeria-others-urged/119848/

Alexander, P. (2012 13 April). A Massive Rebellion of the Poor.Mail and Guardian.Retrieved from http://mg.co.za/print/2012-04-13-amassive-rebellion-of-the-poor.

Amako, K. Y. (2004). The United Nations Economic Commission for Africa.Public Sector Management Reforms in Africa. Retrieved from http://www.uneca.org/publications

Brewster, C., Carey, L., Dowling, P., Grobler, P., Holland, P. and Warnich, S. (2003). Contemporary issues in Human Resource Management.2nd edition. Cape Town: Oxford University Press.

Burger, J. (2009 5 August). The Reasons behind Service Delivery Protests in South AfricaPretoria.Creamer Media Reporter.

Chopra, M., Lawn, J. E., Sanders, D., Barron P., AbdoolKarim, S. S., Bradshaw, D., Jewkes, R., AbdoolKarim, Q., Flisher, A. J., Mayosi, B. M., Tollman, S. M., Churchyard, G. J., Coovadia, H. (2009). Achieving the health Millennium Development Goals for South Africa: Challenges and Priorities. The Lancet, 374: 1023-31.

Chopra, M. et al (2009). Saving the Lives of South Africa's Mothers, Babies, and Children: Can the Health System Deliver? The Lancet, 374: 835-46.

Du Toit, D., Knipe, A., van Niekerk, D., van der Waldt, G. and Doyle, M. 2002.Service Excellence in Governance. Sandown: Heinemann

Economic Commission for Africa. (2003). Report of the Development Policy Management Division (DPMD) Available from http://www.uneca.org

Edoh, T. (2003).Poverty and the Survival of Democracy in Nigeria in Nigerian.Journal of Political and Administrative Studies.1(4).

Fajana, S., Owoyemi, O., Elegbede, T. and Gbajumo-Sheriff M. (2011). Human resource management practices in Nigeria. Journal of Management and Strategy,2(2):57-58.

Fourie, L. De W. and de Jagar, J. (2005). Increasing Customer Satisfaction through Enhanced Service Delivery: An Internal Marketing Approach.Journal of Public Administration. 40 (3):229-240.

Hughes, O. G. 2003. Public management and Administration: An Introduction, third edition, Palgrave Macmillan.

Kanyane, M. H. (2010). Public service delivery issues in question: Opening access to quality social science in Africa. Human Sciences Research Council (HSRC) Press.

Retrieved from www.hsrcpress.ac.za

Katou, A.A., and Budhwar, P.S. (2006). Human resource management systems and organizational performance: A test of a mediating model in the Greek manufacturing context. International Journal of Human Resource Management.17, 1223-1253.

Keyter, C. (2007). New Solutions, Enduring Challenges-The Case for Public Sector Reform in Sub-Saharan Africa Re-examined. African Journal of Public Administration and Management.18(2):1-10.

Kreitner, R. and Kinicki, A. (2010).Organization Behavior. New York: MC McGraw- Hill.

Mihalic S. (2004). The importance of implementation fidelity.Emotional andBehavioural Disorders in Youth. 4:83-86 and 99-105.

Mutahaba, G. andKiragu, K. (2002). Lessons of International and African Perspective on Public Service Reform: Example from Five African Countries. African Development, 27(3\&4), 48-75.

National Planning Commission.(2011). NPC National Development Plan Vision 2030 -lo-res) Department: National Development Plan, Vision for 2030.

National Planning Commission. (2010). Nigeria and the Millennium Development Goals:

Retrieved from http://www.npc.gov.ng/home/doc.aspx?mCatID=68299

Ndume A. (2013 28 May). Nigeria cannot achieve MDGs target by 2015. The Nation on line,

Retrieved from http://thenationonlineng.net/new/nigeria-cannot-achieve-100-mdgs-target-by-2015-ndume/

Nigeria Millennium Development Goals (MDGS) (2010). Countdown Strategy 2010 to 2015: Achieving the MDGs. Retrieved from www.mdgs.gov.ng

Office of the Senior Special Assistant to the President on Millennium Development Goals (OSSAP-MDGs) (2010c). Status Report on the Activities of OSSAP-MDGs in Nigeria. Abuja: Office of the Senior Special Advisor to the President, Millennium Development Goals.

Olaopa, T. (2011)."Strengthening Professionalism in the Public Service: An African Context and Perspective". Discussion paper presented at the Workshop on Promoting Professionalism in the Public Service: Strengthening the Role of Human Resource Managers in the Public Sector for the Implementation of the Africa Public Service Charter, Addis Ababa, Ethiopia, 14 - 18 March. 
Omoyefa, P. S. (2008). Public Sector Reforms in Africa:A Philosophical Re-Thinking

Africa Development.31(4), 15-30.

Organization for Social Science Research in Eastern and Southern Africa (OSSREA). (2013). Thirty Years of Public Sector Reforms in Africa: Selected Country Experiences. Retrieved from: http://www.ossrea.net

Perotti, E. (2003). Discussion Paper No. 2. State Ownership: A Residual Role? Global Corporate Governance Forum: Washington DC. Retrieved from

http://www.gegf.org/library/discussion_papers_and_focus\%20Notes/State\%200wnership.\%20Perotti\%20-\%20-\%20Nov\%202003.pdf.

Powell, D. (2012). Imperfect transition - local government reform in South Africa 1994-2012

Retrieved from www.africansunmedia.co.za

Richards, L. (2011 4 September). Recruitment and Selection policies and procedures.Hearst Newspaper. Retrieved fromhttp://smallbusiness.chron.com/recruitmnet-selection-policies-procedure-2528.html

Richard, P.J., Devinney, T.M., Yip, G.S. and Johnson, G. (2009). Measuring Organizational Performance: Towards Methodological Best Practice. Journal of Management, 35(3), 718-804.

The Guardian Newspapers (2009 27 November, page 1). National Assembly Uncovers Fraud in MDGs, River Niger Projects. Lagos.

United Nations. (2013a). Millennium Development Goals: 2013 Progress Chart

United Nations. (2013b). The Millennium Development Goals Report 2013.United Nations: New York.

United Nations Development Program. (2013). The MDG Report 2013: Assessing progress in Africa toward the Millennium Development Goals

Retrieved from: http://www.undp.org/content/undp/en/home/mdgoverview/

http://www.undp.org/content/undp/en/home/librarypage/mdg/mdg-reports/africa-collection.html

United Nations Development Program, (2010).Millennium Development Goals-Country Report 2010. Republic of South Africa

United Nations Public Administration Network -UNPAN (2008-2010). (2009) African public sector human resource managers' network (APS-HRMnet). Workshop of United Nations Department of Economic and Social Affairs (UNDESA) held at Arusha, Tanzania on the 27 February 2009. Retrieved from http:www.unpan.org/DPADM

United Nations Development Program (2007).Case evidence on Ethics and Values in civil service reforms. New York

United Nations. (2003). Leadership and Social Transformation in the Public Sector: Moving from Challenges to Solutions. Retrieved fromhttp://unpan1.un.org/intradoc/groups/public/documents/un/unpan013665.pdf

World Bank. (2012). World Bank Approach to Public Sector Management 2011-2020: Better Results from Public Sector Institutions. Retrieved from http://blogs.worldbank.org/governance/achieving-better-results-frompublic-sector-institutions.

World Bank.(2003). Understanding Public Sector Performance in TransitionCountries - an Empirical Contribution.Retrieved from www.worldbank.org/publicsector. 